\title{
Editorial: The future vision for social work practice?
}

\section{Kieran O'Donoghue}

This is the first issue of Aotearoa New Zealand Social Work Review following the C50 event, which celebrated our professional social work heritage and explored current issues in practice. Reflecting on this occasion it was notable that our forebears and co-workers had over the last 50 years worked towards a goal of establishing professional social work in Aotearoa New Zealand. The hallmarks of their work were a bicultural critical reflective approach grounded in competence, an entry professional qualification, ongoing professional supervision, continuing professional education and state regulation.

Since the C50 event, the questions that are outstanding are: What is the future vision for social work in Aotearoa New Zealand? And how does social work practice in Aotearoa New Zealand respond to the 21st century issues of: inequality and poverty; dehumanisation, radicalisation and terrorism; environmental instability; a growing digital divide; an interconnected globalised world dominated by an economic voice that speaks of economic productivity, efficiency and outcomes; and the increasing demand and rising costs of health care, food, shelter and other basic necessities?

The effects of these global and social issues is apparent in people's stories about a lack of affordable housing, unemployment, zero hour contracts, children going to school without breakfast, lunch, shoes and raincoats, and people in Aotearoa New Zealand being subjected to discrimination, suspicion, disrespect, abuse and violence. The digital society, on the one hand, provides an unprecedented ability to share information and support others (e.g. Twitter, Facebook, e-advocacy, e-therapy, online petitions and support groups). On the other hand, it has increased the vulnerability of all people, particularly young people, to issues such as cyberbullying, cyberstalking, the risk that one's life, feelings, success and reputation can be harmed in a couple of clicks of a mouse or a tweet. In the workplace, the digital society has created opportunities for all forms of surveillance, recast the boundaries between the personal and professional, and challenged the construction of privacy and confidentiality. In this environment, social work practice has become more complex, specialised, fluid and contractually managed by its funders towards: a) the issues facing children, families and whanau, such as neglect, abuse, violence and offending; b) the provision of support and care for people experiencing health, disability, mental health and addiction issues; c) the social challenges that affect children at school and contribute to challenging behaviours in the classroom and playground; and d) assessing needs and coordinating services so that the people most in need may access and receive support services.

In addition to the above, the social and health care sector is in the midst of significant change across all of its settings. In children's services, the development of children's action plans and children's teams is the most significant change since the Children, Young Persons and their Families Act 1989. This change furthers the differential response approach taken in the late 1990s, wherein non-government agencies undertake more of the duties that once belonged to Child, Youth and Family (CYF). It also returns the focus of statutory social work towards crisis intervention for the children who are most at risk. The society-based 
approach to child protection in the children's action plan means that the responsibility for care protection is extended to everyone involved with children. The children's action plan is currently in the process of looking at children's workforce development. This has implications for social work practice and practitioners working in children's services as well as the wider social work profession. It also raises the question of what is best practice with children, their families and whanau, both now and in the future and how can the profession collectively work towards this?

Health services are also in the midst of a change. This change has been characterised as a shift from hospital-based care to the community. The challenge for social work in this setting is specifying what social work practice involves at the tertiary, secondary and primary health care levels. For health social workers in hospital-based services the challenges include: increasing demand and decreasing resources within the sector; discussions regarding the regionalisation of services; an aging population; the increasing prevalence of chronic diseases; and the rising prevalence of mental ill-health. When seen together these challenges highlight a system that is under stress and facing an impending storm. In contrast to the above is the Primary Health Care (PHC) contracting environment which has seen new developments focused towards primary-level social support in the community. These include social workers working from and across general medical practices, as well as out of new specialist clinical social work private practices which provide mental health and wellness services. The public health discourse concerning the social and economic determinants of health highlights the importance of social work's role in increasing access to health care and addressing factors such as the social gradient, stress, early life (particularly child welfare), social exclusion, work, unemployment, social support, addiction, food and transport (Marmot, 2005, p.1102).

Looking ahead, the path for social workers in health and disability services is clearly one in need of workforce planning, particularly in light of the increasing specialisation. Social workers require a post-qualifying pathway that mirrors that of other health professions. In addition, the need to build up the evidence base for social work practice, raises the question of how to strengthen the research culture within social work. One future possibility may be that of advanced practitioner - researchers working alongside professional leaders and advisers, as there are currently in some parts of Australia.

The non-government organisation (NGO) environment is one in which community services are becoming more entrepreneurial as they compete for funding across the social development, health and disability, justice and education arenas. The emphasis placed on investing for outcomes is also changing practice, with an increased focus on evaluation and demonstrating effectiveness. On the horizon is the Productivity Commission report and the prospect of innovations such as social housing, client-directed budgets and social investment bonds. The latter marries business, government and non-profits to make money, and do some good in the process on the basis that the Government cannot afford to fully fund social services, businesses have the money and non-profits need it. The precarious nature of the NGO environment has seen organisations looking to alternative avenues of funding such as creating pages on 'Give a Little' (https:/ / givealittle.co.nz/) and seeking crowd-sourced funding.

Social work practice in NGOs in both the present and the future is undoubtedly influenced by the portfolio of contracts, interests, programmes and service arrangements. In this 
increasingly competitive environment, the challenge of demonstrating effective outcomes in an efficient manner, social innovation, collaborating and networking will be key features of practice.

Having traversed the issues, challenges and changes for social work across the above three settings (Child and Family Services, Health and NGO), it is my view that there is a clear need for sector-wide engagement on the future of social work and social service practice. Particularly, given the Aotearoa New Zealand Association of Social Workers (ANZASW) plan for expanded membership for social service workers and the inclusion of Careerforce at the Social Workers Registration Board Hui held last September. It is interesting to note that a partnership between Careerforce and Health Workforce New Zealand includes the Kaiāwhina Workforce Programme, which sets out a 20-year vision and a five-year action plan for the development of non-regulated healthcare workers (see http: / / www.workforceinaction.org.nz / ). It is intriguing to note that there is a plan for this sector and yet the regulated profession of social work has yet to establish a workforce development plan.

That said, the Social Workers Registration Board Hui was an important step in ascertaining a sector-wide understanding of the workforce issues in relation to graduates. This conversation needs to continue and develop towards a vision for professional social work practice for the next 20 years and an action plan for the next five years. To not seize this opportunity is to leave the future of professional social work in Aotearoa New Zealand to the winds of change and chance.

Moving on to the articles contained in this issue. The first is Barbara Staniforth's oral history research into Tiromoana and Taranaki House, which paints a rich and revealing picture of some of the history and experiences of these two iconic residential training centres and their role in shaping the development of social work in Aotearoa New Zealand. The emerging field of practice of animals and social work is the topic of the next article authored by Peter Walker, Jenny Aimers and Claire Perry. In this article, the authors examine the importance of the human-animal bond and the role of animals in social work practice and the emerging field of veterinary social work. The next two articles focus on the experiences of migrant groups from differing perspectives. The first of these is Helen Barker Troughton's reflections on her migration transition from London to Aotearoa New Zealand. Helen's auto-ethnographic reflection has much to contribute to social workers who are living through change and looking to harness their resilience. Christine Winbush and Rachael Selby's article highlights the challenges faced by Afrikaners who migrate to New Zealand and the implications these have for social workers and social services that come into contact with these new settlers. The support provided to fathers through parenting programmes is the subject of Lisa Glynn and Michael Dale's article. This article reinforces that the most important issues impacting on father participation in parenting programmes are related to the qualities of the leader, the programme content and the organisational philosophy. The final article explores funeral poverty and funeral welfare policy from the perspective of professionals who had taken responsibility for arranging an indigent funeral. Philippa Thompson and Polly Yeung found the level of current government support to be inadequate and they made practical recommendations about the role social workers have in initiating conversations about funerals with clients and advocating for enhanced access to funeral services and grants to prevent the increase of funeral poverty. 
Finally, this is likely to be my last editorial, as both Mary Nash and I resigned as editors at the end of last year and the Association has recently advertised for a new managing editor. I wish to particularly acknowledge Mary, my co-editor, for her dedication to the journal and support of our contributors. I also wish to thank Helen Simmons, our diligent book review editor, our reviewers, Dinah, who typesets, and Ted, who does the proofreading. It has been an honour to work with all of you as a co-editor of this journal.

\section{Reference}

Marmot, M. (2005). Social determinants of health inequalities. Lancet, 365, 1099-104. [accessed from http:/ / www. who.int/social_determinants/strategy/en/Marmot-Social $\% 20$ determinants $\% 20$ of $\% 20$ health $\% 20$ inqualities. pdf 17 March 2015]. 